\title{
SELECTION OF PROJECTS TO IMPLEMENT A MANUFACTURING STRATEGY
}

\begin{abstract}
This paper presents a quantitative method to support the decision making process within the formulation of a manufacturing strategy. It allows the selection of projects to implement the strategy. It combines the Analytic Hierarchical Process (AHP) and Linear Programming (LP). AHP is used to estimate the priority of the criteria for selecting projects and LP is used to select those projects that optimizes the contribution to the manufacturing strategy. The method was implemented in a manufacturing company and managers found that the tool was appropriate in the process of formulation of a manufacturing strategy.
\end{abstract}

Keywords: manufacturing strategy, projects selection, AHP, linear programming

\section{Introduction}

The literature on manufacturing strategy formulation is vast. However, the proposed processes are mainly conceptual and qualitative. One of the few papers where a quantitative approach is suggested is the one produced by Hallgren and Olhager (2006). However, they do not propose a particular method. This paper proposes the use of Analytic Hierarchy Process (AHP) and Linear Programming to implement the framework in practice.

\section{Literature Review}

Hallgren and Olhager (2006) developed a framework to formulate a manufacturing strategy using a quantitative method. This paper proposes the use of AHP and LP to implement the framework. The combination of AHP and LP has been used in other areas, such as the assignment of human resources (Saaty, 2007) and the evaluation and selection of suppliers (Ayhan and Kilic, 2015).

\section{Objectives}

This paper aims at developing a quantitative method to support the selection of projects to implement a manufacturing strategy.

\section{Research Methodology}

The method was developed from an existing framework on manufacturing strategy. AHP and LP were chosen to implement the framework. The method was applied in a 
Selection of projects to implement a manufacturing strategy, International Symposium of the Analytic Hierarchy Process 2016, London, U.K.

manufacturing company, where a group of managers filled the comparison matrices. It was done by using consensus, mainly to take advantage of the rich discussion produced.

\section{The Proposed Method}

The AHP model consists of the following hierarchical levels: The level 0 is the manufacturing strategy, the level 1 includes the strategic priorities (cost, quality, delivery, flexibility), the level 2 includes the type of decisions (structure and infra-structure) and the level 3 includes the decision areas (technology, facilities, capacity, integration, organization, control systems, quality management and new products introduction). The bottom level corresponds to the criteria for selecting projects. In the study case, they were investment level, net present value, synergy and company experience. AHP was used to estimate the priority of all the elements of the model.

The linear programming model has the following structure:

$$
\text { Maximise } Z=\sum_{i} \operatorname{sco} \Re_{i} \frac{X_{i}}{X_{i}+\epsilon_{i}}
$$

Subject to:

- Budget limitation.

- Requirement of resources

- $x_{i} \leq K y_{i} \forall i$

- $\quad x_{i} \geq 0, y_{i}=0 \vee 1$

The decision variable $x_{i}$ represents the amount of a resource and $y_{i}$ is a binary variable that takes the value 1 when project $i$ is selected. Score ${ }_{i}$ combines the priority of the decision areas with the performance values of the projects. It is important to mention that the LP model can be tailored to various situations.

\section{Limitations}

The main limitation of the method is that it assumes that each project is related to one particular decision area. The Analytic Network Process (ANP) should be explored to eliminate this limitation,

\section{Conclusions}

The proposed method allows the implementation of a conceptual framework for manufacturing strategy formulation. AHP is used to estimate the priority of the criteria for selecting projects aligned with the strategy, while LP is used to make the selection. In 
Selection of projects to implement a manufacturing strategy, International Symposium of the Analytic Hierarchy Process 2016, London, U.K.

the case studied, even the projects selected have not been implemented yet, the managers found that the method was very useful, because it allowed the consideration of the strategy of the company.

\section{Key References}

Ayhan, M. and H. S. Kilic (2015). A two stage approach for supplier selection problem in multi-item/multi-supplier environment with quantity discounts. Computers \& Industrial Engineering, 85, 1-12.

Hallgren, M. and J. Olhager (2006). Quantification in manufacturing strategy: A methodology and illustration. Int. J. Production Economics, 104, 113-124.

Saaty, T. L., K. Peniwati, and J. S. Shang (2007). The analytic hierarchy process and human resource allocation: Half the story. Mathematical and Computer Modelling, 46, 1041-1053. 